\title{
Instrumentos de desarrollo de competencias para un programa de alfabetización en información en bibliotecas escolares
}

\author{
Miguel Ángel MARZAL \\ Universidad Carlos III de Madrid. Departamento de Documentación \\ mmarzal@bib.uc3m.es \\ Nieves SELLERS DE LOS Ríos \\ Universidad Carlos III de Madrid. Máster en Bibliotecas Digitales. marianie- \\ ves.sellerslos@alumnos.uc3m.es
}

Recibido: mayo 2011

Aceptado: octubre 2011

\begin{abstract}
Resumen: Las competencias en información deben ser objeto esencial de los programas de alfabetización en información, como elemento en el desarrollo del modelo socio-económico de la Sociedad del conocimiento. El artículo procede a una reflexión sobre los fundamentos necesarios para la eficacia de estos programas, definiendo, para su mejor aplicación, la evolución de las competencias en su uso dentro de unidades de información, el modelo de bibliotecas digitales educativas y las propiedades de los materiales educativos en web. Se procede a presentar una propuesta metodológica para que, en entornos escolares y en el ambiente de una biblioteca escolar (como CREA, Centro de Recursos para la Enseñanza y el Aprendizaje), se incorporen instrumentos suficientes que ayuden en el ejercicio competencial de los programas de alfabetización en información, analizando como estudio de caso modelos de bibliotecas digitales y plataformas digitales educativas.
\end{abstract}

Palabras clave: Alfabetización en información; Lecto-escritura digital; Biblioteca digital educativa; Recurso web educativo

\section{Development competencies tools for an information literacy program in school libraries}

\begin{abstract}
Considering the fact that the competences on information issues are the main purpose of the information programmes as well as an essential element in the development of the knowledge Society, this article proceeds to reflect on the necessary basis for the effectiveness of these programmes, defining accurately, for their better application, the evolution of the competences in their use in the information units, the educational digital libraries model and the qualities of the teaching materials on the web. Then, we proceed to present a methodological proposal in order to add enough instruments to help in the exercise of competences of the information literacy programmes on a school environment and in the atmosphere of a school library (such as CREA, Teaching and Learning Resources Centres), analyzing digital libraries models and educational digital platforms.
\end{abstract}


Keywords: Information literacy; Digital reading and writing; Educational digital library; Educational web resource

\section{INTRODUCCIÓN}

El desarrollo del actual modelo socioeconómico ha convertido las competencias en información para la Sociedad del conocimiento, lo que la alfabetización fue para la Sociedad industrial. Este contexto ha propiciado, por tanto, la emergencia de la alfabetización en información, como especialidad académica para el desarrollo de competencias lecto-escritoras en información digital. El propio objeto de la alfabetización en información (información en web), proyectado en hiperdocumentos (sobre una infraestructura hipertextual en constante transformación) hace que su concepto, objetivos, medios y métodos estén en constante evolución. Si es común la perspectiva de la alfabetización en información como especialidad que faculta competencialmente en la lectura digital (eficacia en buscar, recuperar y organizar los contenidos en web, para aprender colaborativamente en entornos "sociales" en red), en la escritura digital (eficacia en representar, anotar semánticamente, etiquetar, editar colaborativa, ética e interculturalmente en web) y en evaluar eficazmente la información para innovar conocimiento y saber en web, por su parte la evolución de los contenidos en web va obligando a una dimensión competencial más rica, de modo que se unen nuevas dimensiones conceptuales como la medialiteracy (o "alfabetización en medios"), incluso la transliteracy (o "transalfabetización").

Sin duda los grandes fines estratégicos se alimentan, en su consecución, de objetivos tácticos limitados. Los objetivos competenciales de la alfabetización en información deben desarrollarse a través de tutoriales y sitios web que cimenten sus bases (existen ya unos excelentes ejemplos editados) y superen el estrecho marco de las "buenas prácticas", mediante programas de alfabetización en información, bien diferenciados respecto a la formación de usuarios (gutenberg o en red), en espacios educativos bien definidos como son las bibliotecas digitales educativas (hacia centros de recursos), con un modelo educativo y diseño instruccional muy bien delineados respecto a la lectura o escritura digitales.

Este contexto vertebra el presente trabajo, en el que se hacen necesarias reflexiones sobre la naturaleza de las competencias en información, dentro de programas de alfabetización en información, las propiedades de una biblioteca digital educativa, como entorno competencial idóneo y los caracteres del material de aprendizaje competencial apropiado, para luego presentar una propuesta metodológica de una acción competencial de alfabetización en información, bajo el prisma de los requerimientos de calidad educativa que el Informe PISA recoge sobre un uso eficaz de las tecnologías de información y documentación (TIC). 


\section{FUNDAMENTOS PARA UNA ACCIÓN COMPETENCIAL EN LECTURA DIGITAL}

La consecución competencial en la lectura digital se asienta sobre tres fundamentos:

\subsection{COMPETENCIAS: EVOLUCIÓN, TIPOS Y CONEXIÓN CON LA ALFABETIZACIÓN EN INFORMACIÓN}

La consecución, no tanto de comprensión, sino de conocimiento y saber mediante la lectura digital, implica necesariamente la obtención de competencias en la recuperación, organización y representación de la información, a través de su uso eficaz. Las competencias son, evidentemente, el objeto de un programa de alfabetización en información, en todas sus fases.

La proyección de las TIC en Educación planteó como primera exigencia el desempeño en capacidades tecnológicas, origen de la alfabetización digital. Pareció necesario un modelo de competencias básicas TIC, que apuntó P. Marqués. El modelo reconocía 11 categorías competenciales, que incluían 39 competencias TIC (Marqués, 2008), definidas como la "capacidad de poner en marcha de manera integrada aquellos conocimientos adquiridos y rasgos de personalidad que permiten resolver situaciones diversas".

Sin embargo, también parecían imprescindibles otras capacidades, que no sólo para la comunicación, sino para representar y difundir el mensaje, es decir, el discurso electrónico. La competencia del discurso electrónico aportaba una dimensión actitudinal, pues el educando debe obtener un conjunto de "competencias interpretativas" (destreza en hallar significado a la información), "competencias argumentativas" (capacidad de razonamiento expositivo al negociar la construcción de conocimiento y durante su comunicación) y "competencias propositivas" (capacidad de formular propuestas para generar un nuevo conocimiento).

Las capacidades sobre el discurso electrónico y las competencias sobre las TIC, sin embargo, se complementaban con lo que debían ser las competencias en información, esto es, "la capacidad de desempeñar efectivamente una actividad de información, empleando los conocimientos, habilidades, actitudes, destrezas y comprensión necesarios para lograr los objetivos de información" (Angulo, 2003). Las competencias informativas, pues, se destinan a ejercitar conocimientos y habilidades en la gestión de la información, el uso y aplicación de los contenidos, y la edición y comprensión del conocimiento obtenido. La unión cooperativa entre las competencias sobre TIC y el discurso electrónico, con las competencias en información dentro de programas de alfabetización en información se ha hecho en dos fases significativas: 


\subsection{COMPETENCIAS PARA CONOCER Y SABER}

Ha sido, en nuestra opinión, C.S. Bruce, quien mejor hizo la definición de la tendencia y unión cooperativa al exponer sus tesis en su famosa definición de las siete caras de la alfabetización en información. En su discurso argumentativo, en el que diseña una gradación desde las destrezas a las competencias en información a través de siete peldaños (como la perfección de la sabiduría), reconoce que los dos peldaños iniciales (la base de esa pirámide del conocimiento) se refieren a las destrezas en el manejo de las herramientas TIC y las habilidades en el uso experto de las fuentes de información mediante las TIC. El siguiente peldaño supera las competencias en TIC, para detenerse en la información, mediante el ejercicio de aptitudes y capacidades en recuperar, almacenar, disponer y crear un sistema de control sobre una información conforme a un objetivo de conocimiento. Los siguientes peldaños se dirigen a ejercitar habilidades en la selección y evaluación de contenidos estructurados, para luego ejercitar habilidades y capacidades para la consecución del conocimiento a través de la difusión propia de una nueva información, mediante una exposición argumentada del contenido y su edición digital experta y ética. El último peldaño se reserva para el logro de la competencia en el saber, competencia intelectiva, que faculta al educando para pasar de la investigación de base a la aplicada (saber en qué momento, contexto y acción poner en práctica el conocimiento adquirido). Es el mejor diseño competencial para un programa de alfabetización en información.

\subsection{Las CI2}

El modelo cooperativo entre competencias en TIC y competencias en información ha hallado su expresión evidente en los programas formativos de las bibliotecas universitarias hacia el CRAI a través de las CI2. Su definición y conversión en un elemento de plan de acción en las bibliotecas quedó reflejado en el documento publicado por la Comisión Mixta CRUE-TIC y REBIUN en abril de 2009. La definición se expresa en la web de la biblioteca de la universidad Carlos III:

- Las competencias informáticas son el conjunto de conocimientos, habilidades, disposiciones y conductas que capacitan a los individuos para saber cómo funcionan las TIC, para qué sirven y cómo se pueden utilizar para conseguir objetivos específicos (competencias en relación con el ordenador, los programas y la red)

- Las competencias informacionales son el conjunto de conocimientos, habilidades, disposiciones y conductas que capacitan a los individuos para reconocer cuándo necesitan información, dónde localizarla, cómo evaluar su idoneidad y darle el uso adecuado de acuerdo con el problema que se les plantea. La competencia implica como habilidades: buscar la información que necesita; analizarla y seleccionarla de manera eficiente; organizarla adecuadamente; uti- 
lizarla y comunicarla eficazmente de forma ética y legal, para construir conocimiento.

De este modo, una acción formativa que provocaba confusión, distingo entre alfabetización tecnológica o informática y de información o bibliotecaria (que ya reflejara el artículo de D. Bawden, de 2002) abre una cooperación muy útil para el desarrollo de programas de alfabetización en información en centros de recursos universitarios o escolares (CRAI o CREA)

\subsection{BIBLIOTECAS DIGITALES EDUCATIVAS}

Espacio idóneo para ejercitar las competencias en información en tanto que centros de recursos. Haciéndonos eco de J. Calzada (Calzada,2010) sobre el concepto y tipo de biblioteca digital educativa, como consecuencia de diferentes proyectos para el desarrollo de bibliotecas digitales, el término con el adjetivo "educativas" comenzó a popularizarse hacia 2001 a partir de proyectos cooperativos para el desarrollo de bibliotecas digitales académicas entre el National Science Foundation estadounidense y el británico JISC (Joint Information Systems Committee), como el programa eLib (electronic libraries).

Calzada anota que el término se refiere a aquellas bibliotecas digitales cuyos contenidos y servicios soportan la Educación formal e informal y que tienen como principales valores añadidos, citando el estudio de Agogino de 2007: relevancia en los resultados de las búsquedas; proveedores de información confiables; contenidos y recursos aportados por los usuarios, adecuados a los estudiantes, contextualizados, revisados por pares y con diversas anotaciones diseñadas por los docentes; adecuación a los recursos y estándares educativos; nexo de unión entre los docentes e investigadores. El Instituto de Tecnologías de la Información en Educación de UNESCO, en un paso más, cifraba que los principios de las bibliotecas digitales educativas deben ser: adecuación a las necesidades educativas y científicas; facilitar la innovación educativa; ser accesible, confiable, estable; desarrollar investigaciones y experiencias de contenidos digitales educativos; adaptarse a la innovación TIC; proporcionar herramientas y servicios para la integración de recursos.

Finalmente el Informe expone los criterios de calidad de una biblioteca digital educativa: calidad de los recursos mediante criterios de evaluación de contenidos; acceso integrado, de modo que el usuario perciba que la biblioteca es un elemento integrado en un entorno virtual de aprendizaje y con acceso a diferentes espacios; funcionalidad en la búsqueda y la socialización; individualización para el estudiante, que pueda interactuar y organizar los contenidos (en forma y fondo) conforme a su interés y necesidades; flexibilidad para el docente, en la localización, reutilización y generación de recursos; accesibilidad universal.

Una de las funciones de estas bibliotecas, naturalmente, es el desarrollo, tratamiento y difusión de repositorios digitales, cuyos principales elementos son los obje- 
tos digitales educativos y objetos de aprendizaje. Para ellos debe desarrollar sistemas de descripción mediante metadatos educativos y vocabularios específicos.

\subsection{MATERIAL EDUCATIVO PARA LA LECTO-ESCRITURA DIGITAL}

La Tecnología Educativa, como especialidad dentro de las Ciencias de la Educación, aportaba dos conceptos a los tradicionales materiales didácticos: el medio didáctico, como cualquier material elaborado con la intención de facilitar los procesos de enseñanza y aprendizaje; el recurso educativo, como cualquier material que, en un contexto educativo determinado, sea utilizado con una finalidad didáctica o para facilitar el desarrollo de las actividades formativas (Marqués, 2000). Por su parte M. Area aportaba la definición sistematizada de los conceptos de sitio web educativo (espacios o páginas en la Web que ofrecen información, recursos o materiales referidos a la educación) y, como una especialidad de estos sitios, los materiales didácticos web (materiales curriculares en formato digital que utilizan la Web como una estrategia de difusión y de acceso al mismo) (Area, 2003). Las bibliotecas digitales educativas (hacia CRAI y CREA) y el desarrollo de programas de alfabetización en información han impulsado, paralelamente, otro tipo de instrumento educativo competencial, objetos de aprendizaje (en adelante, $O A$ ) y objetos digitales educativos (en adelante, $O D E$ ).

Los OA han tenido un proceso de definición conceptual y, también, funcional, que es la que más nos interesa. Si el término fue utilizado por W. Hodgins en 1994 (learning objects), con un sentido de pequeñas unidades de texto, sonido, imagen, animación, etiquetados para especificar dominios y procesos de aprendizaje, luego inmersos en unidades mayores de forma flexible y personalizada, será D. Merrill quien acote su concepto, enlazándolo con un propósito pedagógico: los concibe en directa relación a objetos de conocimiento, como formato para contenidos instructivos interrelacionados, cuyo rasgo distintivo es la enunciación de un objetivo, información instruccional y evaluación. La caracterización de sus elementos definitorios y propiedades la hará D. Willey, destaque la reutilización (mediante metadatos de sentido pedagógico) y la granularidad, definitoria de la potencialidad educativa del recurso. L'Allier llegó así a los elementos de definición de los OA: objetivo es un componente estructural que describe los criterios para la consecución de unos resultados previstos en una actividad; actividad, referida siempre a un objetivo, es un componente que inocula un aprendizaje; evaluación, es un criterio e indicador que determina si un objetivo ha sido logrado.

Los ODE, para los que en alguna literatura científica identifica con los OA, se han abierto camino terminológica y conceptualmente a partir de la norma UNEEN 71361, Perfil de Aplicación LOM-ES V1.0, publicada por AENOR en 2009, desde la que se ha llegado a la definición como "contenido educativo digital cuya 
última finalidad es el aprendizaje del usuario y que, en sí mismo, constituye o puede constituir, mediante su integración con otros objetos más simples, un material educativo multimedia". De la definición se desprende que no hay sinonimia con los OA, sino que los OA son un tipo de ODE. Los ODE tiene como propiedad el tipo de contenido (texto, sonido, imagen...) y su funcionalidad instructiva. De hecho los ODE se definen por su funcionalidad en un proceso educativo y por la cobertura curricular de sus contenidos, con niveles de agregación, en los que un nivel corresponde a los OA, y sobre ellos la Secuencia Didáctica y el último y superior, el Programa Educativo.

Estos dos nuevos instrumentos educativos tienen una importancia capital en el desarrollo de las bibliotecas digitales educativas, así como en programas de alfabetización en información, precisamente por las características, de las que unas u otros de distinto modo, disponen OA y ODE: formato digital, que garantiza su multimedialidad y multisecuencialidad (múltiples medios de edición y múltiples modos de lectura por su navegabilidad estructurada); interactividad (uso activo y competente del recurso); reusabilidad (utilización dependiendo del contexto, objetivo y finalidad educativas que se determinen); arquitectura instruccional, aplicable y accesible (conforme a un programa educativo); granularidad (un diseño modular de acuerdo al plan instructivo); interoperabilidad (compatibilidad dentro de redes educativas).

Todos estos fundamentos mancomunados, las transformaciones hacia un modelo educativo competencial para una Educación de calidad (el Informe PISA es un indicador), las transformaciones de las bibliotecas educativas hacia su dimensión digital y centro de recursos y la relevancia de la alfabetización en información, han condicionado el sesgo de la argumentación del presente trabajo.

\section{UNA PROPUESTA DE PROYECTO PARA BIBLITECAS ESCOLARES}

La IFLA/UNESCO define una serie de recursos para la biblioteca escolar, entre otros recursos basados en la tecnología. El conocimiento y el aprendizaje de la mayoría de estos recursos se pueden usar para el desarrollo del alumno en su vida escolar y su vida profesional. Algunos de estos recursos han sido diseñados específicamente para educación, otros se han creado para la comunidad de internautas, pero todos ellos pueden ayudar en la creación de un repositorio dando origen a la biblioteca digital escolar. El desarrollo de esta colección en una biblioteca digital escolar, hacia CREA, debe responder a un proyecto, estructurado: 


\subsection{OBJETIVOS GENERALES}

- Adaptar los recursos que se encuentran en la Web al nivel escolar de los alumnos, para introducirles en el manejo de los ordenadores e instruirles sobre las opciones de búsqueda y de la utilización de la Web.

- Evaluar el contenido seleccionado para su adaptación a las disciplinas curriculares y a la estructura psicológica del alumno.

- Fomentar el trabajo en equipo, utilizando las herramientas disponibles de la red y los materiales complementarios.

- Ejercitar a los alumnos en la memoria comprensiva, adquirible en su vida escolar para desarrollarla en la vida profesional.

- Utilizar recursos y estrategias que permitan responder a la diversidad de los intereses, las motivaciones y las capacidades de los alumnos.

\subsection{OBJETIVOS ESPECÍFICOS}

- Integrar los recursos tecnológicos en las enseñanzas curriculares, para adquisición de destrezas y habilidades a través de la Web.

- Obtener información a través de diferentes plataformas Web, para fortalecer los conocimientos teóricos adquiridos con los materiales que están disponibles en la Web.

- Obtener unos conocimientos adecuados, de calidad, útiles, dependiendo de la herramienta utilizada, de la materia que se haya utilizado y del nivel educativo.

- Adoptar una actitud abierta y curiosa ante cualquier manifestación cultural, científica, lingüística, etc., disponible en la red.

- Aprender a relacionar los contenidos adquiridos en las diferentes asignaturas con la información que obtienen a través de la Web

\subsection{METODOLOGÍA}

La metodología utilizada para el uso de los recursos tecnológicos debe centrarse en la observación, el análisis y la evaluación, por ello atender a la potencialidad interactiva del modelo y el recurso, así como su aplicabilidad a un método didáctico dentro de un plan educativo. Esta tarea es particularmente importante, hoy, porque muchos de los materiales que existen en Internet se crearon para el disfrute de los usuarios, pero conociendo los objetos que lo componen, pueden servir para mostrar unos contenidos relacionados con unas unidades de aprendizaje que se tienen que impartir en los proyectos curriculares.

El método, inductivo desde la observación para la inferencia, se basa en un análisis de diagnóstico de bibliotecas digitales, plataformas digitales y recursos instructivos digitales para llegar a la propuesta de un recurso educativo digital, en 
concordancia hacia el modelo que marcan los OA y los ODE, en el marco de una biblioteca digital educativa (CREA), que se proyecta a través de una plataforma digital, considerada idónea.

La selección de modelos de bibliotecas digitales educativas ha tenido como elemento argumental, la elección de una de tipo multinacional, otras dos a escala europea y española, una biblioteca escolar. El análisis ha seguido como procedimiento: análisis de las características del modelo; el nivel aconsejable escolar, donde utilizar el tipo de biblioteca; los diversos contenidos que podrían ser bien procesados por el modelo; el uso y funcionamiento. En el caso de las plataformas educativas el método de selección se ha basado en la selección de una plataforma patrocinada por una entidad pública, una plataforma creadora de libros digitales interactivos, una wiki y un blog educativos, una plataforma que gestiona un programa para niños pequeños, todos ellos con una clara orientación hacia la Web 2.0.

\subsection{FASES PARA UNA PROPUESTA Y RESULTADO PARA DISCUSIÓN}

Las fases, una vez establecida la fundamentación conceptual de la propuesta, según se ha detallado en el punto 2 de este trabajo, se desarrollan en: consecución de un contexto apropiado a partir de los modelos de bibliotecas digitales educativas; consecución de un medio apropiado a partir del análisis de plataformas digitales educativas; propuesta de un recurso digital educativo, apropiado para un programa de alfabetización en información, como resultado y elemento a debate.

Elemento fundamental a lo largo de estas fases para el análisis metódico de diagnóstico, sin duda es la evaluación. La evaluación fundamenta criterios como la eficacia, la eficiencia y la calidad de los contenidos de los diferentes recursos utilizados. No sólo se deben evaluar los conocimientos adquiridos, sino las destrezas de utilización de los recursos, mediante una función sumativa (valoración de los productos utilizados), añadida a la función formativa (procesos educativos para lograr las metas u objetivos previstos) de la evaluación. La propuesta se acoge a los elementos de evaluación indicados por IFLA/UNESCO: si se están alcanzando los objetivos marcados por la biblioteca, el currículum y la escuela; si se satisfacen las necesidades de la comunidad escolar; si se pueden satisfacer las necesidades a medida que van emergiendo; si los recursos son adecuados; si se es efectivo con relación al coste.

\section{PLATAFORMAS PARA BIBLIOTECAS DIGITALES EDUCATIVAS}

Conforme a los criterios apuntados en la Metodología hemos seleccionado, para un análisis diagnóstico, Google Libros, Europeana, la biblioteca Cervantes y un proyecto de biblioteca escolar como es la biblioteca escolar digital, creada por la 
Fundación Germán Sánchez Ruipérez en colaboración con la Universidad Carlos III. Los materiales que encontramos en las diferentes Web, pueden ser documentos textuales y e-Books como en Google Libros; textos, imágenes, archivos sonoros y vídeos como en Europeana; textos e imágenes en la biblioteca Virtual de Cervantes; la biblioteca escolar digital con diferentes recursos clasificados según los diferentes niveles educativos. El método analítico empleado, también ha sido recogido en la Metodología.

\subsection{GOOGLE LIBROS}

- Características. Sin duda parece recomendable que Google Libros sea un recurso utilizado en una biblioteca escolar para ofrecerlo a la comunidad educativa y obtener el máximo partido de las materias, así como aficionar a la lectura a través de los libros y las revistas digitales. De hecho, Google ha llegado a acuerdos con bibliotecas y universidades, para digitalizar los libros. Las formas en que se puede presentar el libro pueden ser como libro completo (cuando no está protegido por derechos de autor), capítulos, prólogos, índice, incluso algún extracto seleccionado como reclamo publicitario. La interfaz de Google Libros es sencilla y muestra la cubierta de los libros agrupados por temas o categorías. En la parte izquierda, se encuentra una lista de temas, por los que se puede buscar, mientras que en la parte superior aparece el buscador como el de Google, para realizar una búsqueda por título, tema o autor determinado.

Fig. 1: Interfaz de la biblioteca de Google Libros

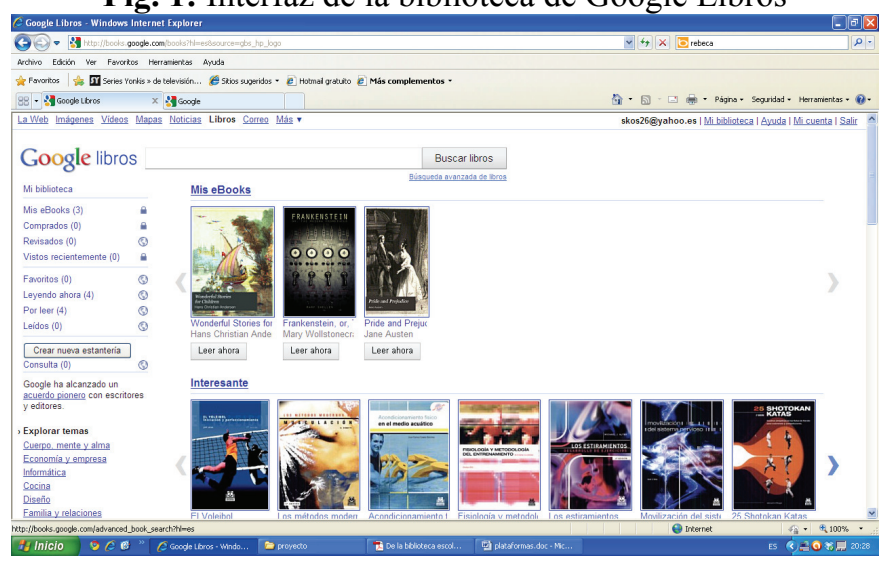

- Usabilidad de Google Libros. Muy amigable, por cuanto se puede determinar una contraseña común para el curso, y que todos los alumnos puedan utilizar los mismos materiales. Cuando se dirija a alumnos de bachillerato, sería más interesante que tuvieran su propia dirección de correo electrónico (sirve cual- 
quier dirección) y lo utilizaran para crear su propia biblioteca digital, formada por los diversos materiales digitales. Una vez que se accede a la interfaz de Google Libros, en la parte izquierda de la interfaz se halla la categoría de Mi biblioteca, dividida en: i) Mis e-Books, que permite acceder a una lista de materias con la clasificación de los e-Books y muestra con qué dispositivos son compatibles para leerlos; ii) Favoritos, con los libros y las revistas que dispone la biblioteca de Google, para ser añadidos en este apartado, además remite a nodos muy interesantes como "leyendo ahora", "por leer" (libros que parecen interesantes) y "leídos"; iii) Crear una estantería, cuyo objetivo es catalogar los libros, las revistas, etc. de forma pública y/o privada. Otra de las categorías de la interfaz es Explorar temas, donde existe una lista de temas creados por Google para acceder a la búsqueda de libros. Una vez se recupera un libro a través del buscador o de algunos de los temas que aparecen propuestos en su clasificación, los datos obtenidos son: un listado con todos los libros que contienen el dato de búsqueda, el título, autor, número de páginas, etc. Puede mostrar una vista previa, que permite acceder a una vista digital del contenido del libro. Precisamente si se utiliza la vista previa, en la parte de la izquierda de la interfaz aparecen las reseñas, $\mathrm{n}^{\mathrm{o}}$ de opiniones que existen sobre el libro, un elemento que permite "escribir reseñas" (opinión personal),"a cerca de este libro", donde pueden editarse comentarios de los usuarios, libros relacionados, páginas seleccionadas, índice, otras ediciones, términos y frases comunes, pasajes populares, referencias a este libro, referencias en páginas Web, información bibliográfica (se puede exportar y luego abrir con Google Crome).

- Temas, polifacéticos en las materias, ya que la biblioteca de Google es variada, no sólo está formada por libros sino que también incluye revistas y magacines. Los contenidos se pueden encontrar en diversos idiomas, aunque predominan las publicaciones del idioma anglosajón, interesante para los centros educativos que se están implantando con una enseñanza bilingüe. Se puede utilizar como origen de una biblioteca escolar, sin profesional en la materia, pues cada libro cuenta con una ficha bibliográfica y los datos más elementales para empezar a catalogar.

- Nivel aconsejable. Muy útil en las enseñanzas medias, en los cursos superiores, al disponer de fuentes de consulta casi de primera mano. En los centros de primaria sería muy útil para iniciación a las lecturas colectivas a través de los medios digitales, ya que desde un ordenador, pda o cualquier otro dispositivo con conexión a Internet se puede proyectar y todos los integrantes del aula pueden participar del contenido. 


\subsection{EUROPEANA}

- Características. Es la biblioteca digital de la Unión Europea, con contenidos textuales, sonoros y visuales (imágenes y vídeos), procedentes de museos, bibliotecas, archivos, etc., de países de la Unión Europea, seleccionados por las diversas instituciones participantes en el proyecto. Su crecimiento es continuo por tratarse de un proyecto de larga duración y ser su finalidad crear un repositorio que sirva de enlace a las grandes instituciones europeas como las bibliotecas, los museos, las filmotecas, etc. Europeana, es un portal Web que sigue las directrices de la WC3, que incorpora elementos como el uso de los metadatos y de la Web 2.0 para que los usuarios puedan interactuar con los contenidos que lo forman.

- Usabilidad. Una vez se accede a la web en www.europeana.eu, la interfaz es muy sencilla. Cuando se accede a Europeana, en la parte superior aparecen categorías para darse de alta y acceder a sus contenidos, así como información sobre la biblioteca y la Comunidad Europea, en tanto que en la parte central de la página Web se encuentra un buscador, para comenzar la búsqueda por un autor, una ciudad, un tema, etc. La interfaz se complementa con otros posibles accesos: Comparta sus ideas, para archivos en las diferentes redes sociales; Otros usuarios han propuesto, para temas de actualidad; Explore y navegue, con búsquedas a través del tiempo; Nuevo contenido, para incorporación de nuevos archivos a la biblioteca digital Europeana. Cuando se anota en el buscador un término, al presentar los resultados la biblioteca ofrece las opciones "todo" (todos los archivos asociados al término), "Textos", "Imágenes", "Vídeos", "Sonidos" dependiendo del tipo de código que queramos asociar al término buscado. También ofrece, naturalmente elementos para refinar la búsqueda (proveedor, idioma, país, fecha, etc.). Europeana se puede utilizar sin necesidad de registrarse, ya que se puede realizar cualquier consulta desde el buscador, pero es recomendable registrarse con cualquier correo electrónico, ya que es una forma de interactuar con los elementos que aparecen en la plataforma y las diferentes redes sociales. 
Fig. 2. Interfaz de una búsqueda realizada en Europeana

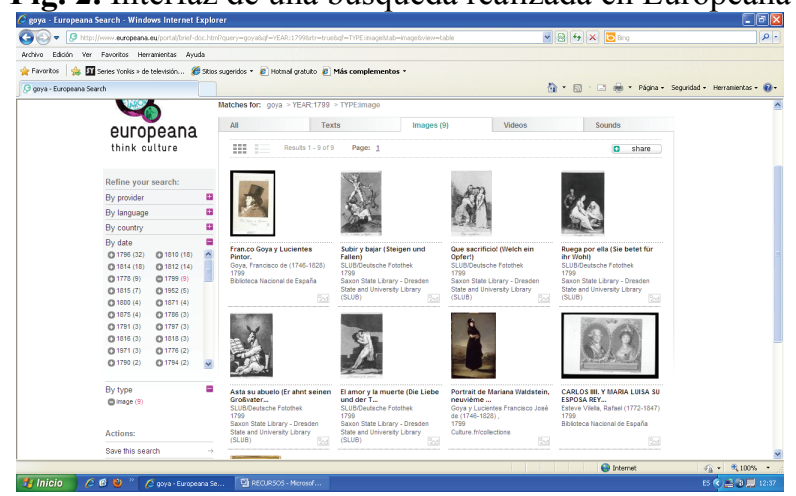

- Temas. Europeana es muy eficaz para materias referidas a "Humanidades" e idiomas. Puede ser un recurso utilizado desde dos vertientes: material complementario para el profesor, utilizando los diferentes archivos que existen como acompañamiento de las lecciones teóricas que se deben impartir; material de trabajo para el alumno, con la búsqueda de recursos de las diferentes lecciones que se han tratado en una clase. Sus posibilidades como auxilio para crear una biblioteca digital son grandes en dos dominios muy relevantes en la Web: para archivos sonoros, pues permite que cada alumno guarde una pieza musical de cada compositor que se ha tratado en clase, así como compartir su archivo con sus compañeros, ya que desde Europeana se puede acceder a diferentes redes sociales; formar una biblioteca de arte, de acontecimientos históricos, de mapas, etc. a elección de los profesores.

- Nivel aconsejable. El nivel aconsejable para trabajar con este portal Web, es para los alumnos de la secundaria y el bachillerato.

\subsection{LA BIBLIOTECA VIRTUAL MIGUEL DE CERVANTES}

- Características. La biblioteca virtual Miguel de Cervantes nace con el propósito de divulgar la literatura española e hispanoamericana, incorporando fotografías, vídeos y audio. Su interfaz pretende mostrar la información de una forma visual, estructurándola en cuatro grandes bloques con diferentes enlaces, para que el usuario desde el principio pueda seleccionar el bloque así como la temática que se encuentra agrupada en ese bloque: Catálogo, Biblioteca de Autor, Áreas, Actualidad 
Fig. 3. Interfaz de presentación de la Biblioteca Virtual Miguel de Cervantes

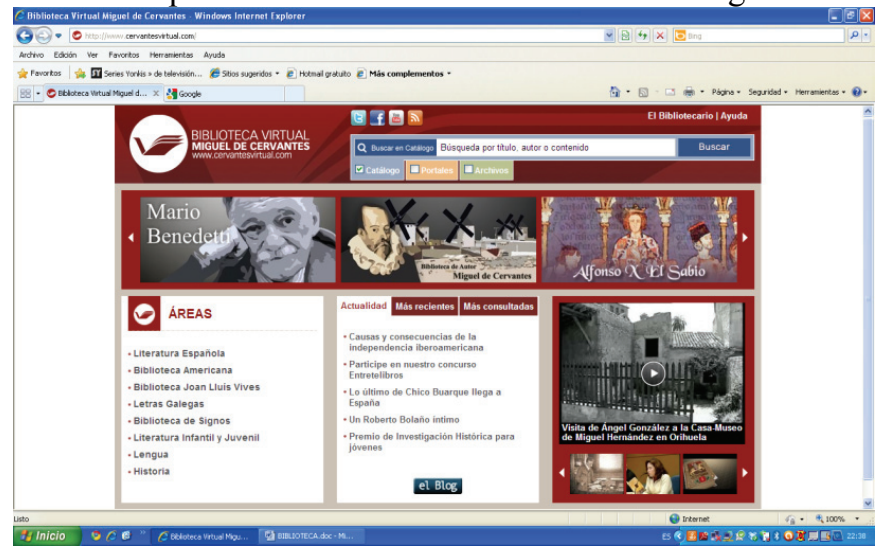

- En el i) Catálogo las búsquedas que se pueden realizar son por título, autor o contenidos de las obras que recogen, como también seleccionar en los portales que engloba o en los archivos. Existe una opción de ayuda y están asociadas redes sociales. El logotipo de la entidad sirve para retornar a la página principal en cualquier nodo de navegación. El bibliotecario, es el enlace que muestra la opción de comunicación con la biblioteca siendo a través de una dirección de correo electrónico. ii) La Biblioteca de Autor se caracteriza por una selección de imágenes que muestran los diferentes portales Web de las distintas bibliotecas que engloban. iii) Las Áreas son las diferentes materias que integran esta biblioteca, asociando a cada Área una ficha técnica. Las áreas que la forman son: la biblioteca de Literatura Española formada por una presentación, catálogo, portales institucionales, portales temáticos, bibliotecas de autores, páginas de autor, archivos, enlaces y realización; bibliotecas temáticas de la Lengua, Historia, Americana; la biblioteca de Signos con materiales y educación Bi-Bi (experiencias bilingües de educación para niños sordos); la biblioteca Joan Lluís Vives representación para la cultura catalana, valenciana y balear; la biblioteca de Letras Galegas con obras digitalizadas de la cultura gallega desde el siglo XIII hasta la actualidad; la biblioteca de Literatura infantil y juvenil, formada por una presentación, catálogo, portales institucionales, portales temáticos, bibliotecas de autores, clásicos de literatura infantil y juvenil, crítica e investigación, didáctica, enlaces y realización. iii) Actualidad, donde se recogen las noticias más relevantes relacionadas con la cultura y también acoge el blog de la entidad.

- Usabilidad. No es necesario darse de alta, sólo se tiene que ir a la página principal y seleccionar el ítem en que se desea entrar y se accede a las áreas que lo forman.

- Temas. La disposición de la página web nos indica con certeza dónde es más eficaz su información: Literatura, por presentar una selección de los autores 
más representativos de cada época de la literatura, con fragmentos de sus obras, imágenes que la acompañan, etc., para que sea más fácil el aprendizaje; Historia, por una selección de personajes históricos españoles e hispanoamericanos con su biografía y las obras o los acontecimientos con los que está relacionado e imágenes; Lengua, al abordar el origen de la lengua castellana, y su repercusión a lo largo de los siglos. La biblioteca posee mucho material de los escritores en idioma castellano, (al igual que de incorporaciones de la cultura catalana y galega), con los que el alumno puede trabajar, seleccionando las partes más interesantes, compartiéndolas con sus compañeros, comentándolas, participando en los foros de debate, etc.

- Nivel aconsejable. Muy útil para los alumnos de primaria, así como los alumnos de secundaria, incluso para aquellas comunidades con propio idioma, como Cataluña, Valencia, Islas Balearas y Galicia. Se hace evidente en la biblioteca de Literatura infantil y juvenil, por sus enlaces enfocados al fomento de las lecturas con documentos textuales, didácticos, biografías, etc., adaptadas, acreditado en el enlace de Didáctica, estructurado por niveles, con material complementario para el profesor. Es muy destacable su utilización en colegios de educación especial, ya que presenta la biblioteca de signos, ideal para alumnos con deficiencias auditivas.

\subsection{BIBLIOTECA DIGITAL ESCOLAR}

- Características. Es un proyecto del grupo de investigación DOTEINE de la Universidad Carlos III y del Centro de Tecnologías Avanzadas de la Fundación Germán Sánchez Ruipérez. Es una biblioteca digital adaptada a los programas educativos de la enseñanza española. Se caracteriza por la calidad de los contenidos, los recursos y los enlaces que la integran. Los contenidos están divididos por materias y por las diferentes etapas educativas de la enseñanza, desde infantil hasta bachillerato. Es una biblioteca gratuita, de acceso libre, aunque es conveniente darse de alta para crear una biblioteca propia, poner etiquetas, guardar las búsquedas, participar en los foros.

- Usabilidad. Formada por repositorios, recursos, actividades, etc., pretende ser un complemento para reforzar temas, conocimientos, realizar actividades y como refuerzo en las tareas escolares. La Interfaz de presentación se divide en: educación infantil, educación primaria y eso-bachillerato. La mejor forma de utilizar la biblioteca escolar es registrarse, pueden hacerlo profesores, padres, educadores y los propios alumnos. Una vez que se ha registrado, la interfaz presenta dos niveles: el nivel superior presenta dos columnas, la de la izquierda acoge las etiquetas catalogar, mis favoritos, mis búsquedas, recomendados y mis comentarios, la parte de la derecha búsqueda, enlaces, noticias, profesionales y ayuda; el nivel inferior ocupa las $2 / 3$ partes de la pantalla y se caracteriza por ser como un panel informativo, con los nodos destacamos y noti- 
cias. La página Web contiene un buscador, donde seleccionar búsqueda, sencilla o avanzada, pero también de forma textual o de forma visual. Una vez que se ha realizado la búsqueda, muestra sus resultados con todos los recursos que existen sobre esa unidad, así como el tesauro, con las palabras clave ordenadas alfabéticamente, complementado con palabras relacionadas sobre esa unidad didáctica. El acceso a un recurso conlleva una carta de presentación, que es una ficha técnica, donde encontramos un título, unos identificadores, una breve descripción de sus contenidos, y el nivel educativo al que va dirigido. Subsidiariamente hay una serie de fichas secundarias, sobre cuándo se ha creado, quién, si necesita algún programa adicional para que funcione, etc. El recurso se ha revisado antes de incluirlo en el catálogo de la biblioteca, y ha pasado por un proceso de validación para optar a incluirse en la biblioteca escolar digital. Otras opciones a tener en cuenta en la biblioteca digital escolar son los siguientes apartados: i) Enlaces, dirigidos a Educación Infantil, Primaria, Secundaria y Bachillerato, con el listado de sus respectivas materias curriculares; ii) Noticias, para presentación de recursos, blogs, noticias, conferencias, encuentros, etc.; iii) Profesionales, para personas, centros, equipos, etc., relacionados con el mundo de la educación;IV) Ayuda.

- Temas, corresponden a todas las áreas que forman el currículum escolar y se adaptan a todas las etapas que integran la vida escolar.

Fig. 4. Resultado de visualización de una búsqueda]

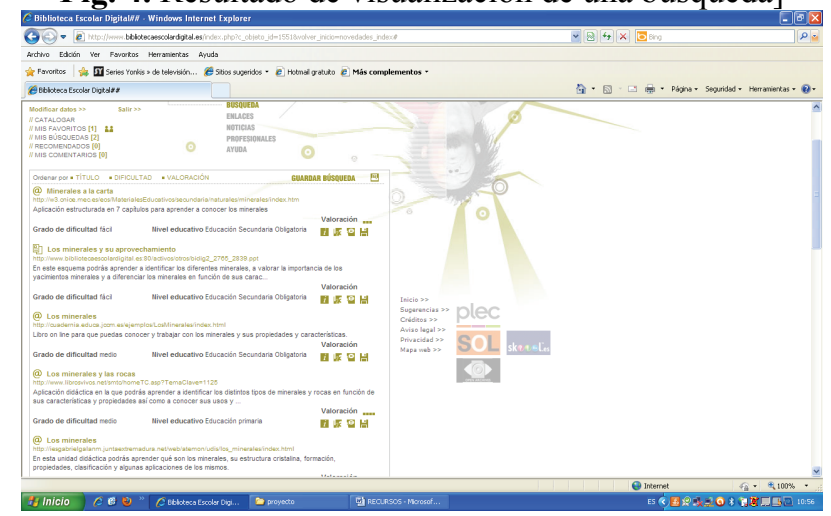

- Nivel aconsejable, para todo el ciclo educativo preuniversitario pues incluye, según hemos detallado, recursos desde infantil hasta bachillerato. Es, además, una biblioteca que se va actualizando y creciendo a medida que aumenta la comunidad escolar. 


\section{PLATAFORMA DIGITALES EDUCATIVAS (2.0)}

Siguiendo los criterios anotados en la Metodología del punto 2, esta categoría se nutre de plataformas que aparecen en la Web destinados a la educación, seleccionando un recurso patrocinado por una entidad pública, una wiki de una organización, un blog creado por un profesional en educación y un programa desarrollado para niños, todos ellos diferentes formatos de presentación que componen la Web 2.0.

\subsection{INSTITUTO DE TECNOLOGÍAS EDUCATIVAS}

Es una unidad del Ministerio de Educación, donde posee una serie de materiales digitales para apoyar las TIC en la educación no universitaria, poniéndolos a disposición de los profesores, alumnos y padres, para todas las unidades de aprendizaje. La interfaz da acceso a nodos como ITE, Escuela 2.0, Agenda, Contactos, Usuarios ITE, Formación, Recursos, Mediatica. Analizaremos estos tres últimos:

- Formación, que da acceso a: Formación en red del profesorado, para cualquier docente que se quiera preparar sus clases con ayuda de la tecnología, junto con cursos, recursos en diversas materias y experiencias; Aula Mentor, referida a personas que buscan formación permanente, mediante cursos en línea, CIDEAD, centro también para personas adultas y alumnos con circunstancias especiales, Instituto de Formación del Profesorado, Investigación e Innovación Educativa (IFIIE), plataforma de mediación entre el conocimiento de una materia educativa y la toma de decisiones

- Recursos, para los profesores, incluyendo formación a distancia, centro virtual de educación, cooperación internacional y recursos educativos curriculares, complementarios y zona de descarga, de hecho los recursos educativos curriculares se componen de materias obligatorias y optativas, lectura y contenidos transversales (se observa una lista ordenada alfabéticamente, compuesta de todas las unidades de aprendizaje de cada materia desde el nivel infantil al bachillerato, con sus niveles educativos), incluso cada recurso posee una ficha técnica, que detalla desde el nivel al que va dirigido, a cómo se debe utilizar y para qué área de aprendizaje está enfocada; para la comunidad educativa, entendida como "Niñas y niños" (recursos sobre la ciudad, el mundo, las lenguas, la naturaleza, etc.), "Jóvenes" (recursos para artes, lenguas, pensamiento, naturaleza, sociedad y ciudadanía, cuerpo y salud, ciencia y tecnología, formación profesional y complementaria), "Madres y padres" (con recursos educativos para salud, orientación, educación, etc., pero también formación a distancia), "Personas adultas" que se orienta a dar información, recursos y formación destinados a las enseñanzas e-learning; Diccionarios, de 
diferentes tipos, como Salamanca de la lengua española, Richmond en inglés y el Bibliográfico Ángel Pariente de la poesía española del siglo XX

- Mediateca, que se compone de sonidos y de imágenes que se pueden utilizar para crear una actividad.

Fig. 5. Vista de la interfaz de la pestaña de recursos

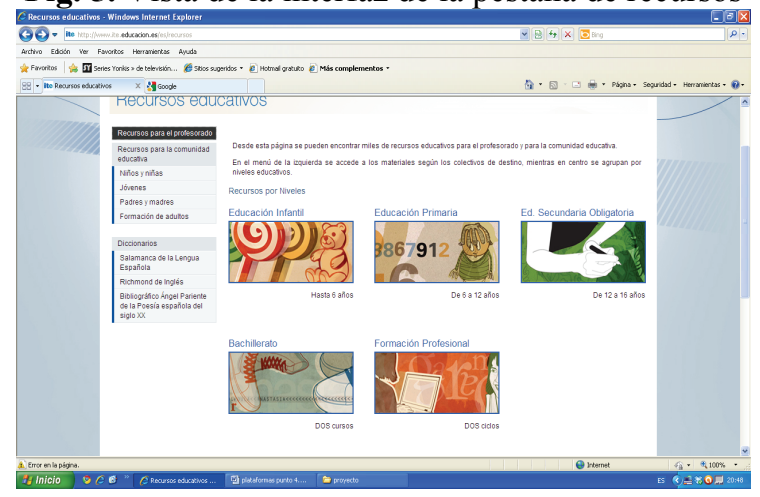

\subsection{WIKISABER}

Es una plataforma con contenidos, recursos, buenas prácticas y comunidad, creada por la Fundación Wikisaber e Intel y respaldada por la London grid for learning, la universidad de Salamanca, la Fundación Pastor de estudios clásicos y la Fundación Germán Sánchez Ruipérez. Utilizan herramientas de la Web 2.0 para que el usuario, cree, edite, etc., sus contenidos, tanto en español como inglés. Wikisaber se puede utilizar desde la Web, visualizando los diversos materiales, pero conviene registrarse como usuario, bien responsable de un centro, profesor, padre o alumno. La interfaz de presentación se compone de contenidos, recursos, buenas prácticas, comunidad, actualidad y wikisaber.

Los Contenidos se agrupan en educación infantil, primaria y secundaria, cuyo repertorio de recursos implica el acceso del recurso y una guía de uso, mientras la temática para educación infantil es identidad y autonomía personal, medio físico y social y comunicación y representación, para educación primaria matemáticas, conocimiento del medio e inglés, para educación secundaria matemáticas, ciencia de la naturaleza, física y química, biología y geología, cultura clásica y tecnología. Los Recursos, es un nodo formado por herramientas y recursos que se pueden utilizar para explicar los diferentes contenidos curriculares. Las Buenas prácticas, incluyen información sobre experiencias, tutoriales, ayuda de cómo elaborar el currículum, etc. para profesores, padres y alumnos. La Comunidad, se compone de una serie de innovaciones tecnológicas que componen la Web 2.0 como son foros, wiki, blogs, etc. La Actualidad agrupa a noticias, agenda y legislación. Por último, 
Wikisaber, explica su funcionamiento, y desde este nodo se puede acceder a los apartados de registro, contacto, preguntas frecuentes, etc.

Fig. 6. Interfaz de los contenidos de Wikisaber

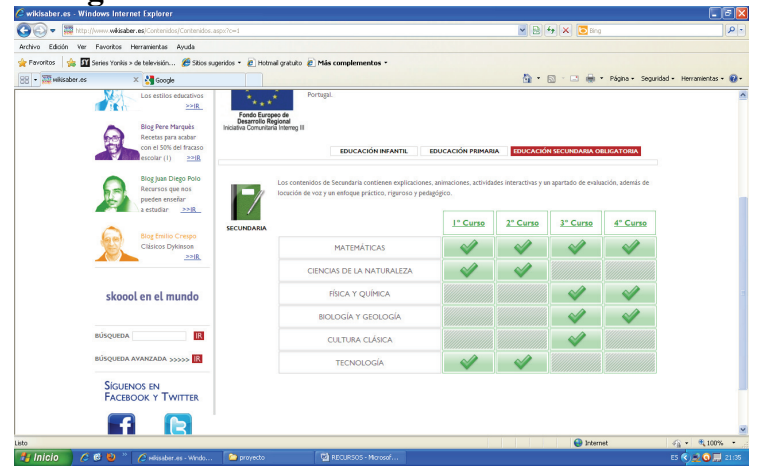

\subsection{BIBLIOTECA ON-LINE DE RECURSOS DE EDUCACIÓN PLÁS- TICA Y VISUAL.}

El acceso está en http://sites.google.com/site/luciaag2/home. En realidad se trata de un blog creado por una profesional de la educación en la materia de plástica, por lo que sus contenidos versan sobre esta materia. Está creado de una forma sencilla con una serie de etiquetas de lo que consta cada tema. La lista de etiquetas que aparece en el blog sigue un orden alfabético y abarca desde aplicaciones técnicas, pasando por arte, cómic, dibujo y por los nuevos elementos de la Web 2.0 como son Wiki y tutoriales. Al acceder a una etiqueta, se encuentran los recursos relacionados con esa unidad de aprendizaje, con su título, una descripción y el enlace.

Fig. 7. Interfaz de la biblioteca de educación plástica y visual

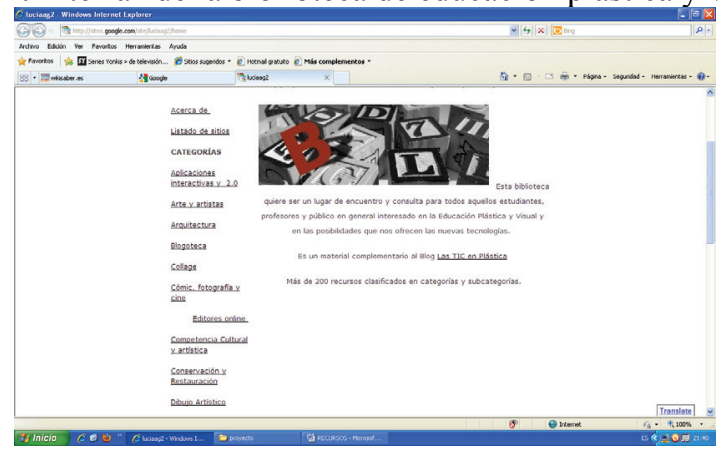




\subsection{KID-PAD}

Es un programa de ordenador diseñado por la Universidad de Maryland, para que los niños puedan inventar historias, hacer dibujos y trabajar de una forma sencilla desde la pantalla del ordenador. Se creó en 1998, por lo que aunque en la actualidad, existen programas interactivos mucho mejores y con más utilidades, éste todavía se puede utilizar en el primer curso de infantil. Para poder utilizar el programa ha de descargarse, momento en que aparece una pantalla con una serie de iconos como son los lápices, el borrador, las letras, etc. En este programa también se pueden insertar imágenes, archivadas previamente. No es necesario estar conectado a la red, para poder utilizarlo, por lo que cualquier profesor lo puede utilizar en su clase, teniendo sólo el ordenador y una pantalla para proyectar la interfaz. La interfaz del programa se asemeja a una pizarra mágica.

Fig. 8. Interfaz de una imagen insertada en el programa Kid-pad

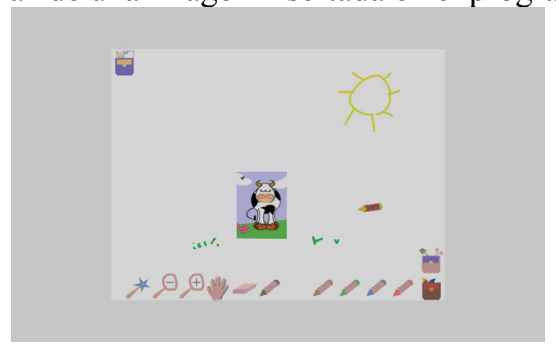

\section{UNA EXPERIENCIA: EDILIM}

Una de las plataformas con recursos que se pueden utilizar en el ámbito bibliotecario, al igual que en el ámbito escolar es Edilim. Se trata de un sistema desarrollado para la creación de materiales educativos y se compone de una "biblioteca" donde se publican las actividades que han desarrollado profesionales de la educación, el "sistema Lim", que está formado por el editor de actividades, el visualizador y el archivo en formato XML, "tipos de páginas" que se han desarrollado en el sistema Lim y una página de contacto, para enviar el libro creado.

\subsection{UTILIZACIÓN DE EDILIM}

Desde la página de inicio, http://www.educalim.com/cinicio.htm, se descarga el archivo zip de la herramienta EdiLim en el ordenador, se guarda en el correspondiente archivo y se abre la carpeta con los ficheros necesarios para la instalación del programa. Entre todos los ficheros que aparecen, existe uno llamado EdiLim.exe, que es el que se va a utilizar para instalar el programa. Instalado el programa, se diseña la actividad que se quiere desarrollar y el lugar en donde se va a realizar, 
como puede ser la biblioteca, el aula, la hemeroteca, etc., como también los contenidos que se van a incluir en ese libro, que pueden estar formados por archivos de textos, imágenes, vídeos y archivos sonoros, o por la combinación de ellos, al igual que permite crear páginas, siguiendo las indicaciones de los tutoriales.

La creación de un libro interactivo está pensada para que los alumnos de los centros escolares aprendan y afiancen los conocimientos adquiridos en las aulas, por lo que es una tarea del educador desarrollar las actividades basadas en los objetivos de las unidades didácticas. El sistema pretende ser sencillo en su uso, al igual que el resultado, el libro, tiene que ser intuitivo, de fácil manejo, claro y conciso. De hecho, la interfaz de presentación del libro destinada a los usuarios es muy intuitiva y de fácil manejo, para que de un simple vistazo se comprenda lo que se debe realizar. Aparece el título del libro y el nombre de la página, que expresa lo que se tiene que realizar en la parte superior. Además se deben tener en cuenta otros elementos imprescindibles como las flechas de la parte inferior de la interfaz que sirven para avanzar o retroceder las páginas y el triángulo al terminar la actividad para saber si se ha realizado correctamente.

\subsection{GUIIA DE LA HERRAMIENTA EDILIM}

Si bien la herramienta EdiLim es sencilla de manejar, se hace necesario conocer algunas características de su funcionamiento. En la página inicial se hace el ofrecimiento de "Abrir" para acceder a un libro ya creado o "Nuevo" para editar un libro propio. En ambos casos, el sistema remite a una interfaz característica.

Fig. 9: Interfaz de la página de inicio de la creación de un libro interactivo

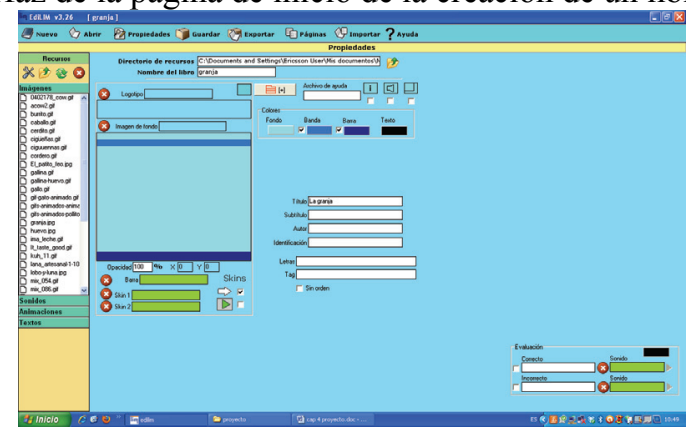

En la parte superior de la interfaz se muestran los botones para la creación de la actividad, imprescindibles conocerlos para realizar cualquier actividad.

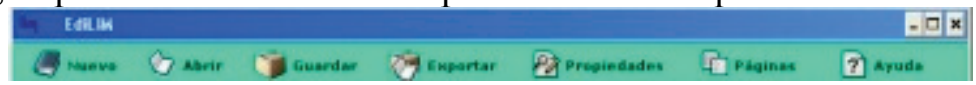

De modo que, "Guardar" nos permitirá archivar el libro y sus cambios, "Exportar" proporciona los pasos necesarios para publicar el libro, las "Páginas" dan acceso tanto a los formatos de actividades que se pueden realizar, como a los archi- 
vos que se pueden utilizar para la creación de esas actividades, por fin la "Ayuda", conecta con los tutoriales de EdiLim.

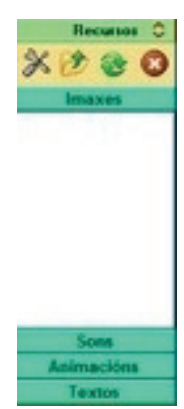

La parte de la izquierda, es la zona utilizada para guardar los archivos que vamos a necesitar a lo largo de la creación del libro. Los archivos pueden ser de tipo imagen, sonidos, animaciones y textos y se van a poder modificar utilizando el dibujo de las herramientas. Se pueden eliminar utilizando el botón rojo con el aspa. La parte central, se caracteriza por la gestión de los datos y de la presentación que va a poseer el libro interactivo. El libro interactivo se constituye por una serie de páginas donde están desarrolladas las actividades. En la fig. 10, las páginas pueden ser para realizar ejercicios de palabras, de frases, de números, de escritura, de imágenes, etc. Se pueden combinar las páginas como se deseen, repetirlas, etc.

Fig. 10: Interfaz de los tipos de páginas que posee el programa EdiLim

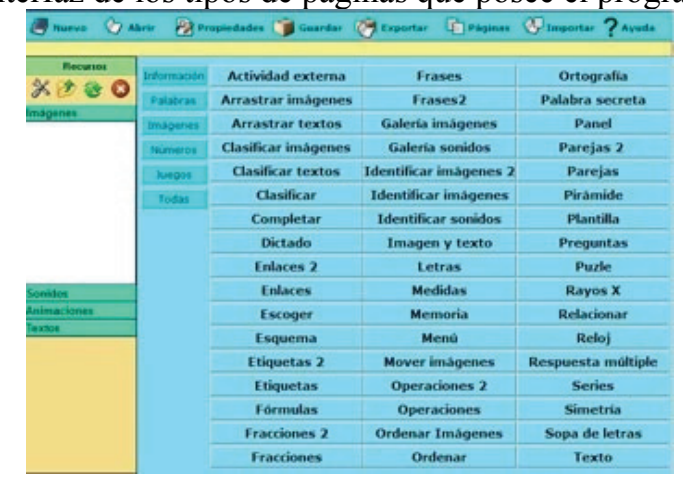

\subsection{CREACIÓN DE UN LIBRO INTERACTIVO: LA GRANJA}

En nuestro caso, realizamos un libro sencillo destinado a la población infantil que incluyera actividades junto con lecturas de cuentos, para motivar la lectura en una biblioteca y en el aula, guiados por el bibliotecario o el profesor. Para la creación del libro completo se puede acceder a través del siguiente enlace http://dl.dropbox.com/u/9391365/granja.html.

En este caso se pensó en una población infantil de entre 6 y 8 años, que ya se han iniciado en la lectura y que podían realizar las actividades de lectura y de escritura de una manera virtual. Para realizar la actividad se seleccionaron imágenes de Internet y cuentos infantiles que aparecen publicados en la Web, respetando los derechos de autor, aunque también se podía haber escaneado algún texto y haber utilizado fotografías, si bien lo que nos interesaba era aprender el funcionamiento 
de esta herramienta. Se creó una carpeta con todas las imágenes y los textos que pensábamos utilizar, que se fueron guardando en el directorio donde se encontraban las imágenes del libro y se fueron insertando, a medida que se avanzaba en la creación del libro. Los textos se copiaron o se escribieron a directamente. Los sonidos se agruparon en la carpeta de sonidos. El resultado es una página como se observa en la fig. 11, donde se observa que pueden utilizar texto que ya aparece escrito e imágenes.

Fig. 11: Interfaz con texto e imagen

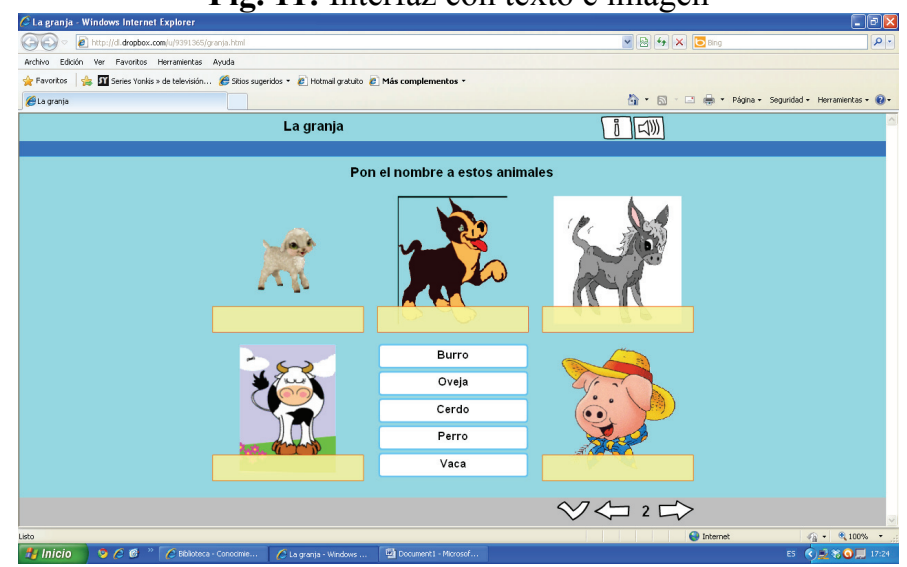

Otras páginas inciden más en el texto, por lo que son útiles las flechas de desplazamiento hacia arriba o/y hacia abajo para avanzar en la lectura. Pueden editarse imágenes para averiguar la palabra oculta y una etiqueta, donde escribir esa palabra. En otros casos, se utilizan páginas de dibujos para aplicar didácticas diferentes y aprender con imágenes como en la fig. 12

Fig. 12: Interfaz de imágenes

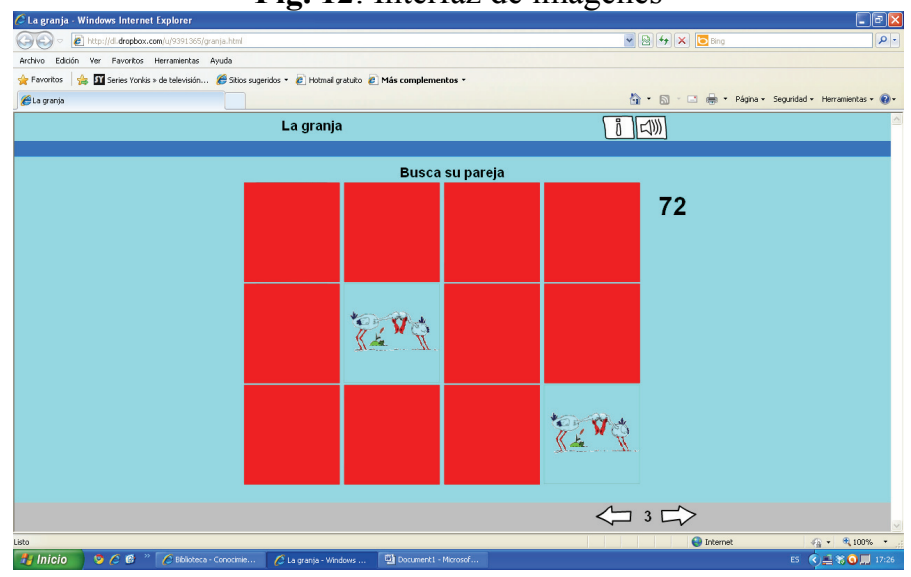


Una vez realizado el libro, es importante su visualización en Internet. En nuestro caso se tuvo que utilizar el programa Dropbox, que permite hacer públicos los archivos para poder visualizar. Es preciso hacer públicos todos los contenidos de la carpeta, no sólo el libro. Realizada la publicación, se rellena el formulario que aparece en la página de EdiLim http://www.educalim.com/biblioteca/ submit.php , $\mathrm{y}$ aparece publicado en su biblioteca.

La actividad nos ha obligado a una evaluación, que arroja: inconvenientes, derivados de la necesidad de una previa "alfabetización tecnológica", sólo se puede hacer público el libro con todo su contenido, no sectorializarlo según el objetivo didáctico en cada momento, además no existe un foro donde las personas puedan opinar sobre los libros que se han creado, aunque sí que existe un foro de ayuda; ventajas, a partir de la creación de una actividad para complementar una lección, o fomentar la lectura y la escritura, siguiendo los propios criterios y adaptándola al curso y al nivel deseado, además una vez que la actividad aparece publicada, se puede reeditar en cuestión de muy poco tiempo.

\section{CONCLUSIONES}

En la actualidad existen modelos de plataformas para bibliotecas, espacios y materiales didácticos web, acordes con el avance de una sociedad que reclama nuevos métodos de enseñanza y de aprendizaje tanto para alumnos y profesores, como cualquier usuario TIC, que desde un ordenador y conectándose en un entorno web puede aprender desde el manejo de algún programa informático, hasta actividades educativas más sofisticadas.

La alfabetización de la sociedad con el desarrollo de los hiperdocumentos en la Web debe implicar que, a través de los enlaces de las diferentes estructuras, se puedan adquirir unas destrezas y habilidades en la información y la educación, por ello, ahora es el momento idóneo de que existan unas bibliotecas digitales que engloben a las diversas bibliotecas constituidas para la búsqueda de los conocimientos y de la sabiduría. Las habilidades informáticas al igual que la escritura y la lectura deben desarrollarse desde la infancia conjuntamente, adecuando los nuevos objetos de aprendizaje a los diferentes niveles educativos, dentro de una biblioteca digital educativa y en un proyecto curricular basado en las CI2.

El aprendizaje en el entorno digital, pues, es una tarea que implica a toda la comunidad escolar. La población adolescente ya utiliza el entorno digital como medio de comunicación social, pero el entorno digital no sólo es un medio de comunicación, sino que es y debe ser un medio de aprendizaje que debe ser complementario de la educación formal. Por ello, precisamente, en este trabajo se ha desarrollado una selección de bibliotecas y plataformas con unas estructuras muy definidas, con unos conocimientos elaborados, con unas categorías muy marcadas, donde los documentos aparecen etiquetados por niveles, estructuras, materias que son un complemento ideal para la educación. Los centros educativos no sólo deberían estar formados por 
los profesionales de la educación, sino que deberían integrar a profesionales de otros ámbitos como la comunicación y la documentación, al igual que se incluyó a la pedagogía y la psicología en el ámbito educativo.

La sociedad ha evolucionado con las nuevas tecnologías, por lo que la enseñanza debe evolucionar en este campo, no se trata sólo de instalar equipos informáticos en las escuelas sino que también se debe enseñar a utilizarlos, pero aún más hacer competentes en el uso y evaluación de los contenidos web, para su transformación eficaz en conocimiento. La sociedad demanda nuevas habilidades y destrezas en el entorno tecnológico, por lo que los centros educativos deberían ser el primer escalón de la pirámide donde se desarrolle y se conozca el entorno web y donde se empiece a desarrollar una actividad de lectura y de escritura digital.

Un aspecto merece la mayor atención, como desarrollo futuro: la necesidad de que estos recursos tengan por objeto generar repositorios en las bibliotecas digitales educativas, con propias etiquetas, vocabularios de representación, pero además la edición se oriente hacia un formato de objetos digitales educativos y, más específicamente, objetos de aprendizaje. Su proyección competencial en programas de alfabetización en información, así como su eficacia en el aprendizaje y conocimiento serían claramente notorios.

\section{REFERENCIAS BIBLIOGRÁFICAS}

ALVÁREZ, L. Biblioteca on-line de recursos de Educación plástica y visual. [en línea] Disponible en: http://sites.google.com/site/luciaag2/home. [Consulta: 20 mayo 2011]

ANGULO MARCIAL, N. "Normas de competencia en información". BiD: textos universitaris de biblioteconomia $i$ documentació, 2003, 11. http://www.ub.edu/bid/11 angul2.htm [Consulta 20mayo 2011].

AREA, M. "De los web educativos al material didáctico web". Comunicación y Pedagogía, 2003, 188: 32-37. [en línea]. Disponible en: http://balboa.unex.es/crai/personal/evte/webseducativos.pdf [Consulta 20 mayo 2011]

BAWDEN, D. "Revisión de los conceptos de alfabetización informacional y Alfabetización digital". Anales de Documentación,2002, 5: 361-408. Disponible en: http://revistas.um.es/analesdoc/article/view/2261 [Consulta 20 mayo 2011]

BIBLIOTECA VIRTUAL MIGUEL DE CERVANTES. . [en línea] Disponible en: http://www.cervantesvirtual.com/ [Consulta 20 mayo 2011]

CALZADA PRADO, J. Repositorios, bibliotecas digitales y CRAI: los objetos de aprendizaje en la educación superior. Buenos Aires: Alfagrama, 2010

CORDÓN GARCÍA, J. et al. Las nuevas fuentes de información: Información y búsqueda documental en el contexto de la Web 2.0. Madrid: Pirámide, 2010.398 p. 
CRUE-TIC\&REBIUN. Las competencias informáticas e informacionales en los estudios de grado (2009). Documento elaborado por la Comisión mixta. 2009. [en línea]. Disponible:

http://www.rebiun.org/doc/documento_competencias_informaticas.pdf [Consulta 20 mayo 2011]

DAVIS, B.H. \& BREWER, J. P. Electronic discourse: linguistic individuals in virtual space. Albany, NY: GState University of New York Press, 1997

DROPBOX. Servicio de almacenamiento. [en línea] Disponible en: https://www.dropbox.com/home [Consulta 21 mayo 2011]

EUROPEANA. Biblioteca virtual digital de la Unión Europea [en línea] Disponible en: http://www.europeana.eu/portal/ [Consulta 20 mayo 2011]

ESPAÑA. MINISTERIO DE EDUCACIÓN. Instituto de Tecnologías Educativas. [en línea] Disponible en: http://www.ite.educacion.es/ [Consulta 20 mayo 2011]

FUNDACIÓN GERMÁN SÁNCHEZ RUIPÉREZ. Biblioteca escolar digital. [en línea] Disponible en: http://www.bibliotecaescolardigital.es/ [Consulta 20 mayo 2011]

FUNDACIÓN WIKISABER. Wikisaber. [en línea] Disponible en: http://www.wikisaber.es/Wikisaber/SobreWikiSaber.aspx?c=1 [Consulta 20 mayo 2011]

GOOGLE LIBROS. Google. [en línea] Disponible en: http://books.google.es/bkshp?hl=es\&tab=wp [Consulta 20 mayo 2011]

LIM. Educalim. [en línea] Disponible en: http://www.educalim.com/clegal.htm [Consulta 20 mayo 2011]

MARQUÉS GRAELLS, P. Las competencias digitales en los docentes. 2008. [en línea] Disponible en: http://peremarques.pangea.org/competenciasdigitales.htm [Consulta 20 mayo 2011]

UNIVERSIDAD DE MARYLAND. Kid-pad. [en línea] Disponible en: http://www.cs.umd.edu/hcil/kiddesign/kidpad.shtml [Consulta 20 mayo 2011] 